\title{
Non-vascularised Fibular Autograft for Reconstruction of Paediatric Bone Defects: An Analysis of 10 Cases
}

\author{
Gerard A Sheridan ${ }^{1}$, John T Cassidy², Aaron Donnelly³, Maria Noonan ${ }^{4}$, Paula M Kelly ${ }^{5}$, David P Moore ${ }^{6}$
}

\begin{abstract}
Aim and objective: Fibular autograft is a known technique for the reconstruction of traumatic and non-traumatic bone defects in both adult and paediatric populations. We aim to describe our outcomes using various stabilisation methods for non-vascularised fibular autograft to reconstruct both benign and malignant tumours in a paediatric population in a National Paediatric Centre over the past 14 years.

Materials and methods: This was a retrospective review of 10 paediatric cases with non-traumatic primary bone defects in a National Paediatric Centre. Criteria for inclusion were all non-traumatic primary bone defects requiring reconstruction with a non-vascularised fibular autograft in the diaphyseal or metaphyseal regions of the bone. The primary outcome measures were union and time to union (weeks). Time to union was illustrated using Kaplan-Meier curves. Secondary outcome measures included postoperative fracture, infection (deep and superficial), time to full weight-bearing and all-cause revision surgery.

Results: The mean length of follow-up was 63 months for the entire cohort (9-168, SD =48.6). There was no loss to follow-up. Six lesions were located in the tibia, two in the femur and the remaining two were located in the ulna and third metacarpal. Union was ultimately achieved in 8 of the 10 patients using this donor autograft. The mean time to union was 28 weeks $(10-99, S D=29.8)$. There were four complications of autograft fracture. The mean time to fracture was 17 weeks $(9-32, S D=10.71)$. In all four of these cases, the patient achieved union at final follow-up. There were two superficial and two deep infections recorded. Three resolved with the use of antimicrobial therapy and one deep infection ultimately required insertion of an intercalary prosthesis to treat the infected non-union of the fibular graft site.

Conclusion: The use of non-vascularised fibular autograft for the reconstruction of tumours is an effective surgical technique in a paediatric cohort. We report the largest known series of malignant paediatric tumours treated with this technique to date.

Clinical significance: Non-vascularised fibular autograft is successful in the reconstruction of large bone defects secondary to malignant paediatric bone tumours.

Keywords: Aneurysmal bone cyst, Autograft, Case series, Chondroblastoma, Ewing's sarcoma, Fibrous dysplasia, Fibula, Osteosarcoma, Paediatric tumour.

Strategies in Trauma and Limb Reconstruction (2020): 10.5005/jp-journals-10080-1462
\end{abstract}

\section{Aim and Objective}

Fibular autograft has been utilised for the reconstruction of traumatic and non-traumatic bone defects in both adult and paediatric populations for many years. The use of this technique to reconstruct malignant paediatric tumours has not been extensively described in the literature to date, however. Numerous stabilisation techniques have been described including the llizarov circular frame method, internal fixation with plate and screws and intramedullary frictional fit of the donor fibula within the recipient bone. We aim to describe our outcomes using these stabilisation methods for non-vascularised fibular autograft to reconstruct both benign and malignant tumours in a paediatric population in a National Paediatric Centre over a 14-year period.

\section{Materials and Methods}

Institutional Review Board approval was granted for this study which was ethically conducted in accordance with Declaration of Helsinki. This was a retrospective review of 10 paediatric cases with non-traumatic primary bone defects in a National Paediatric Centre. All surgeries were performed by surgeons experienced in the reconstruction of paediatric primary bone defects. Criteria for inclusion were all non-traumatic primary bone defects requiring reconstruction with a non-vascularised fibular autograft in the diaphyseal or metaphyseal regions of the bone. Patients with secondary lesions, lesions located in the epiphysis or lesions $\overline{{ }^{1-6} \text { Department of Orthopaedics, Our Lady's Children's Hospital, }}$ Crumlin, Dublin, Ireland

Corresponding Author: Gerard A Sheridan, Department of Orthopaedics, Our Lady's Children's Hospital, Crumlin, Dublin, Ireland, Phone: +353851070944, e-mail: sheridga@tcd.ie

How to cite this article: Sheridan GA, Cassidy JT, Donnelly A, et al. Nonvascularised Fibular Autograft for Reconstruction of Paediatric Bone Defects: An Analysis of 10 Cases. Strategies Trauma Limb Reconstr 2020;15(2):84-90.

Source of support: Nil

Conflict of interest: None

reconstructed with vascularised graft were excluded from the analysis.

Clinical and radiographic data points were extracted from the hospital clinical records and electronic imaging systems. Patient demographics were recorded along with the specific lesion characteristics. Histopathology reports were consulted to confirm the diagnosis of tissue samples. Recipient defect size and donor autograft size were also recorded. The primary outcome measures were union and time to union (weeks). Radiographic union was defined as continuity of three of the four cortices on orthogonal radiographic imaging. Clinical union was defined as a painless graft site. This was analysed by the senior author and the application of

(c) The Author(s). 2020 Open Access This article is distributed under the terms of the Creative Commons Attribution 4.0 International License (https://creativecommons. org/licenses/by-nc/4.0/), which permits unrestricted use, distribution, and non-commercial reproduction in any medium, provided you give appropriate credit to the original author(s) and the source, provide a link to the Creative Commons license, and indicate if changes were made. The Creative Commons Public Domain Dedication waiver (http://creativecommons.org/publicdomain/zero/1.0/) applies to the data made available in this article, unless otherwise stated. 
objective definitions for union was useful in avoiding any bias in our results. Radiographic imaging was performed at intervals of 2, 6, 12, 18 and 24 weeks. More frequent imaging was performed if deemed necessary on a case-by-case basis. Time to union was illustrated using a Kaplan-Meier curve. Secondary outcome measures included postoperative fracture, infection (deep and superficial), time to full weight-bearing and all-cause revision surgery. The STROBE checklist was adhered to for this study. ${ }^{1}$

Statistical analysis was performed using Stata/IC 13.1 for Mac (64-bit Intel). Descriptive statistics were used to describe any relevant findings.

Ten patients were analysed in total. Both malignant and benign lesions were included in the cohort, the commonest of which was Ewing's sarcoma ( $n=3)$ followed by osteosarcoma $(n=2)$ and fibrous dysplasia $(n=2)$. Chondroblastoma, bone infarction and aneurysmal bone cyst made up the remaining lesions of the sample. Patient demographics illustrated a preponderance of females and a wide variation in age (11 months to 15 years) (Table 1).

All donor fibular autografts were harvested using a longitudinal incision over the long axis of the fibula. Careful subperiosteal dissection was performed and the relevant donor length was excised based on the requirement dictated by preoperative imaging. A small oscillating saw was utilised to complete the osteotomies of the fibula and the non-vascularised graft was then prepared depending on the recipient requirements. The average defect size of the recipient was $10 \mathrm{~cm}(4-21.5 \mathrm{~cm})$. Bilateral grafts were harvested in four patients and for two patients, the graft was further cut into two pieces after removal. Where possible, the proximal and distal graft ends were inserted into the larger medullary canal of the recipient bone ends. This afforded an initial interference fit at the graft-host interface. Fixation was then secured using the llizarov method of circular framing in the majority of cases $(n=7)$. One patient received a locking plate, another underwent wiring to secure the graft and the $A B C$ of a third metacarpal had no fixation as it was not required.

\section{Results}

The mean length of follow-up was 63 months for the entire cohort (9-168, SD = 48.6). There were no patients lost to follow-up. Six lesions were located in the tibia, two in the femur and the remaining two were located in the ulna and third metacarpal. Seventy per cent were female and the mean age at diagnosis was 9.5 years (11 months to 15 years) (Table 1 ).

\section{Union}

Union was ultimately achieved in 8 of the 10 patients. The mean time to union was 28 weeks $(10-99$, SD $=29.8$ ) (Table 2). The Kaplan-Meier curve illustrates that most unions occurred between the 3-month and 6-month periods (Fig. 1).

By 6 months, there were two cases of delayed union (patient 1 and patient 9). Patient 1 was a 14-year-old female with fibrous dysplasia of the right tibia (Fig. 2). This was resected and grafted with bilateral fibular autografts. At 22 weeks, the patient was admitted for pin site pain. No infection or loosening was identified at that time. At 35 weeks, the tibial frame was removed and clinical assessment of graft site stability confirmed a clinical union. This same patient subsequently developed a valgus procurvatum deformity of the limb 6 months later which was managed with gradual correction in a Taylor-spatial frame for 6 months. Three months later, a dynamic compression plate (DCP) was applied to the tibia after a further realignment osteotomy was performed for persistent deformity. This remained in situ for 9 months and was then replaced by an llizarov frame as union had still not been achieved at the osteotomy site. This frame was adjusted twice and removed completely after 15 months. The patient had a residual limb length discrepancy of $4 \mathrm{~cm}$ and was discharged from our institution shortly after this.

Patient 9 was a 15-year-old female with a Ewing's sarcoma affecting the left tibia. Initially, this lesion was excised and bilateral donor fibulae were grafted into the site which was then stabilised with an Ilizarov frame in January 2014. At 32 weeks postoperatively, a graft fracture was noted. The patient remained in frame which was resisted 8 months after the initial procedure. The frame was removed at 8 months but the patient sustained a refracture at the graft site 3 months later again. This was managed with open reduction and internal plate fixation. Final union was then achieved 5 months later in December 2015 at a total of 99 weeks (Fig. 3).

\section{Complications}

Fracture

Four patients sustained a fracture of the autograft (patients 3 , 4, 5 and 9). Three tibias and one femur were affected by this complication. The mean time to fracture was 17 weeks (9-32,

Table 1: Patient details

\begin{tabular}{|c|c|c|c|c|c|c|c|c|}
\hline Patient & Age & Gender & Pathology & Location & Donor fibula & $\begin{array}{l}\text { Defect size } \\
(\mathrm{cm})\end{array}$ & $\begin{array}{l}\text { Donor size } \\
(\mathrm{cm})\end{array}$ & Fixation type \\
\hline 1 & 14 & $\mathrm{~F}$ & Fibrous dysplasia & Tibia & Bilateral & 21.5 & $23(\times 2)$ & Ilizarov frame \\
\hline 2 & 13 & $\mathrm{~F}$ & Osteosarcoma & Tibia & Ipsilateral & 4 & 15 (cut into 3) & Ilizarov frame \\
\hline 3 & 5 & $\mathrm{~F}$ & Ewing's sarcoma & Femur & Bilateral & 12 & $14(\times 2)$ & Ilizarov frame \\
\hline 4 & 15 & M & Osteosarcoma & Tibia & Contralateral & 6 & 12 (cut into 2 ) & Locking plate \\
\hline 5 & 2 & $\mathrm{~F}$ & Chondroblastoma & Tibia & Bilateral & 9 & $10(\times 2)$ & Ilizarov frame \\
\hline 6 & 3 & M & Fibrous dysplasia & Tibia & Contralateral & 10 & 11 & Ilizarov frame \\
\hline 7 & 11 months & $\mathrm{F}$ & $\begin{array}{l}\text { Venous infarction (secondary } \\
\text { to varicella zoster) }\end{array}$ & Ulna & Contralateral & 6 & 7 & Wires \\
\hline 8 & 13 & M & Ewing's sarcoma & Femur & Ipsilateral & 18 & 20 & Ilizarov frame \\
\hline 9 & 15 & $\mathrm{~F}$ & Ewing's sarcoma & Tibia & Bilateral & 10 & 14 & Ilizarov frame \\
\hline 10 & 14 & $\mathrm{~F}$ & Aneurysmal bone cyst & $\begin{array}{l}\text { Third } \\
\text { metacarpal }\end{array}$ & Contralateral & 4 & 4.5 & $\mathrm{~N} / \mathrm{A}$ \\
\hline
\end{tabular}


Non-vascularised Fibula for Paediatric Bone Defects

Table 2: Patient outcomes

\begin{tabular}{|c|c|c|c|c|c|c|c|c|c|}
\hline Patient & Union & $\begin{array}{l}\text { Time to union } \\
\text { (weeks) }\end{array}$ & $\begin{array}{l}\text { Number of } \\
\text { procedures } \\
\text { performed }\end{array}$ & $\begin{array}{l}\text { Postoperative } \\
\text { fracture }\end{array}$ & $\begin{array}{l}\text { Time to fracture } \\
\text { (weeks) }\end{array}$ & Infection & $\begin{array}{l}\text { Infection } \\
\text { (superficial/deep) }\end{array}$ & $\begin{array}{l}\text { Time to full weight- } \\
\text { bearing (weeks) }\end{array}$ & $\begin{array}{l}\text { Follow- } \\
\text { up time } \\
\text { (months) }\end{array}$ \\
\hline 1 & Yes & 35 & 6 & No & - & No & - & 23 & 72 \\
\hline 2 & Yes & 23 & 1 & No & - & No & - & 31 & 47 \\
\hline 3 & Yes & 10 & 2 & Yes & 9 & Yes & $\begin{array}{l}\text { Deep — femur } \\
\text { osteomyelitis }\end{array}$ & 10 & 168 \\
\hline 4 & Yes & 13 & 1 & Yes & 20 & No & - & 13 & 56 \\
\hline 5 & Yes & 10 & 1 & Yes & 10 & Yes & $\begin{array}{l}\text { Superficial - pin } \\
\text { site }\end{array}$ & 6 & 9 \\
\hline 6 & Yes & 16 & 1 & No & - & Yes & $\begin{array}{l}\text { Superficial - pin } \\
\text { site }\end{array}$ & 16 & 122 \\
\hline 7 & Yes & 19 & 1 & No & - & No & - & - & 36 \\
\hline 8 & No & $\mathrm{N} / \mathrm{A}$ & 2 & No & - & Yes & $\begin{array}{l}\text { Deep — wound } \\
\text { breakdown }\end{array}$ & $\begin{array}{l}\mathrm{N} / \mathrm{A} \text { (conversion to } \\
\text { megaprosthesis) }\end{array}$ & 56 \\
\hline 9 & Yes & 99 & 3 & Yes & 32 & No & - & 109 & 52 \\
\hline 10 & No & $\mathrm{N} / \mathrm{A}$ & 2 & No & - & No & - & - & 12 \\
\hline
\end{tabular}

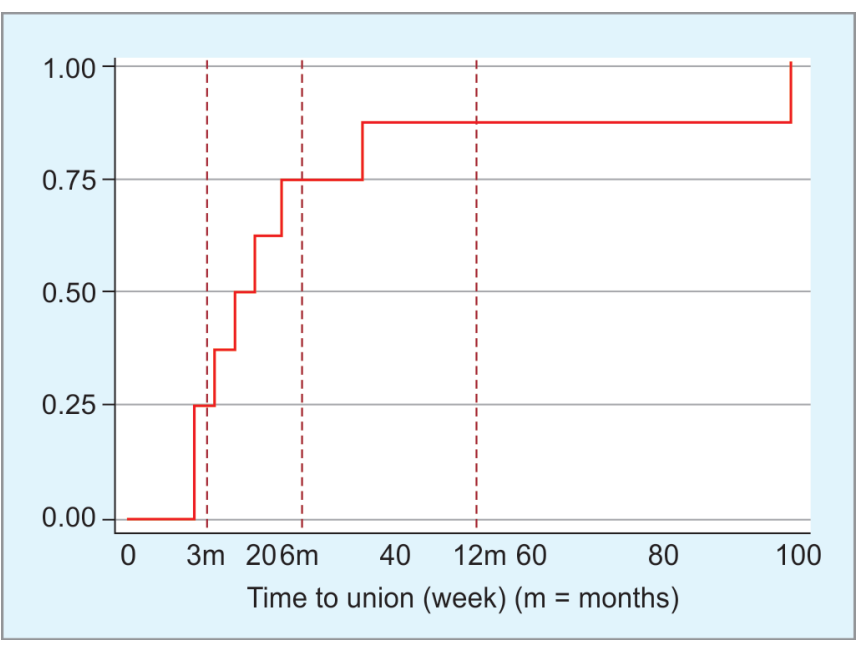

Fig. 1: Kaplan-Meier curve for patients achieving union $(n=8)$

$S D=10.71)$. In all four of these cases, the patient achieved union at final follow-up.

\section{Infection}

Four patients sustained an infection. Two of these were superficial pin site infections (patients 5 and 6) and two were deep infections (patients 3 and 8). Patient 3 was a 5-year-old female with Ewing's sarcoma of the femur (Fig. 4). She commenced chemotherapy in May 2010. In January 2011, the tumour was excised and bilateral fibular grafts were positioned in to the $12 \mathrm{~cm}$ defect and stabilised with an Ilizarov frame. The patient had a further 3 months of chemotherapy as part of the management of her underlying malignancy. Four years later, after sustaining soft tissue trauma to the operated leg, the patient developed femoral osteomyelitis. The focus of infection was incised and drained. Methicillin-sensitive staphylococcus aureus was grown from specimen cultures and the infection resolved after 6 months of IV antibiotic therapy. No further surgery was required.

Patient 8 was a 13-year-old male, also presenting with a femoral Ewing's sarcoma (Fig. 5). This was excised and reconstructed using fibular autograft, stabilised with an Ilizarov frame. Eight months after the initial surgery, the patient developed a deep wound infection with wound breakdown. The patient was admitted for wound management and IV antibiotic therapy. This patient ultimately developed an infected non-union of the graft site which was excised and reconstructed with a femoral intercalary endoprosthesis once the deep infection had been eradicated.

\section{Non-union}

Two of the 10 patients proceeded to non-union (patients 8 and 10). As discussed above, patient 8 developed a deep wound infection and subsequent infected non-union. This was treated with an intercalary endoprosthesis after sterilisation of the infected tissue bed. Patient 10 was a 14-year-old female with a diagnosis of aneurysmal bone cyst of the third metacarpal (Fig. 6). The ABC was excised in November 2018 and reconstructed with a nonvascularised fibular autograft. The patient experienced persistent pain and did not proceed to union. A psychiatric history of selfharming exacerbated the ability of the patient to manage this complication and so the patient opted for amputation of the third metacarpal and middle finger.

\section{Revision}

Five patients underwent revision surgery for all causes. Patients $1,3,8,9$ and 10 were all revised for numerous indications. Patient 1 underwent six procedures as described due to persistent limb deformity. Patient 3 was revised for a femoral fracture as described and underwent two procedures in total. Patient 8 underwent two procedures in total, and ultimately received an intercalary prosthesis for infection. Patient 9 underwent three procedures for the management of two graft fractures. These were treated with two frames initially followed ultimately with a plate for internal fixation. Patient 10 underwent two procedures, ultimately ending with amputation of the middle finger. The mean time to revision was 11 months (8-18.5, SD =4.27) (Fig. 7). Patients 1, 5, 7 and 9 all proceeded to union. As described above, patients 8 and 10 went on to established non-unions which were treated with an intercalary endoprosthesis and amputation, respectively.

\section{Function}

Patient 8 was the only patient with a lower limb lesion that did not achieve full weight-bearing status of that limb. The infected nonunion in this case was treated with an intercalary endoprosthesis. There were seven other patients with lower limb lesions that were 




Fig. 2: Patient 1

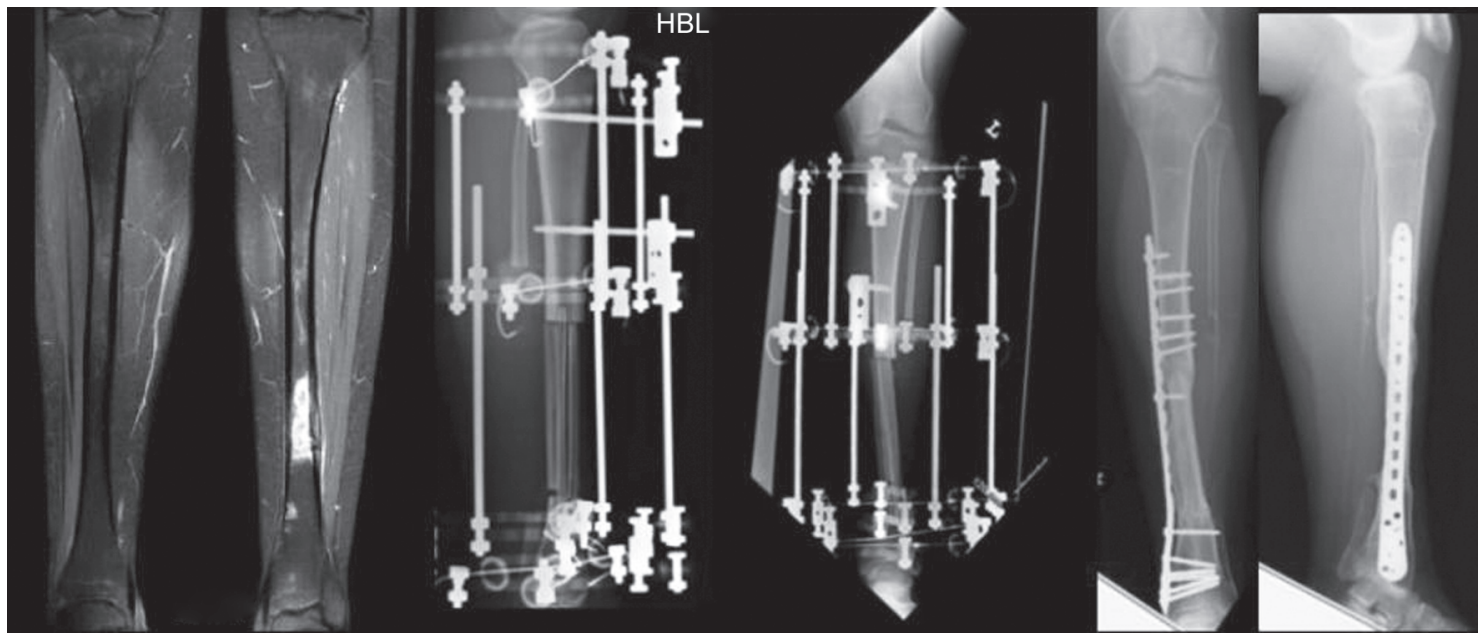

Fig. 3: Patient 9

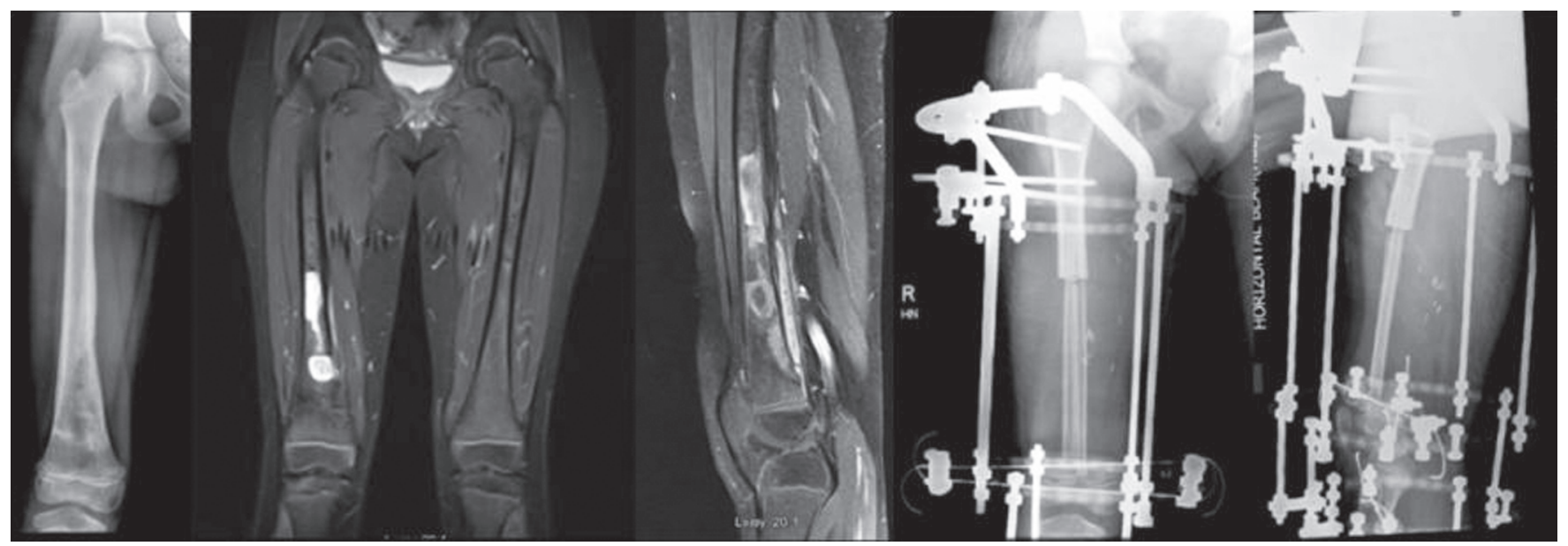

Fig. 4: Patient 3

reconstructed and these did all achieve full weight-bearing status. The mean time to full weight-bearing was 29.7 weeks (6-109, SD = 35.9). We also report no cases of ankle valgus deformity post-graft harvest.

\section{Discussion}

The fibula is a very versatile source of autogenous graft and has been used for decades in the field of limb reconstruction. Its use has been well described in the reconstruction of the distal radius 




Fig. 5: Patient 8 postoperative infection and intercalary endoprosthesis

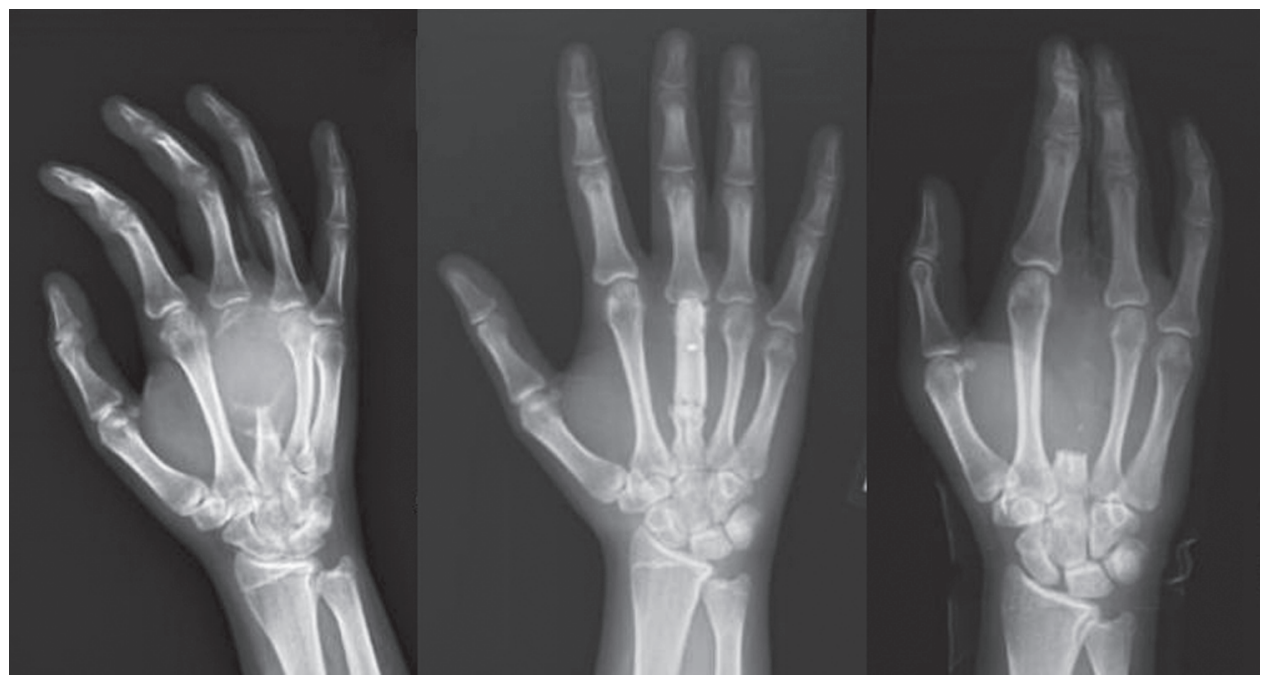

Fig. 6: Patient 10 preoperative, postoperative and post-amputation radiographs

post-giant cell tumor resection. ${ }^{2}$ Fibular autograft has also been used to provide structural support for the cervical spine after corpectomy in spondylotic disease. ${ }^{3}$ A diverse range of anatomic structures including the humerus, metatarsal, pelvis and the hip have all been reconstructed with this technique. ${ }^{4-7}$ Applications for use also extend to the field of maxillofacial surgery for mandibular reconstruction of malignant tumors. ${ }^{8}$

Lenze et al. suggest that in the setting of large segmental defects, vascularised graft is superior to non-vascularised graft. ${ }^{9}$ Focussing on large segment defects, the traditional teaching of the $6 \mathrm{~cm}$ rule has now been questioned..$^{10}$ In other work, Lenze et al. confirmed a correlation between mechanical complications of the reconstruction and a reconstructed defect length equal to or above $12 \mathrm{~cm} .{ }^{11}$ Three patients in our cohort had a defect exceeding $12 \mathrm{~cm}$ in length. Only one of these developed a non-union and this was secondary to deep infection. We therefore describe no failures for aseptic non-union in a group of three patients with large defects $\geq 12 \mathrm{~cm}$. This finding may have implications for the scope of application for fibular autografts in the future. Across the entire cohort, we achieved $80 \%$ union rates with a non-vascularised graft for a mean defect size of $10 \mathrm{~cm}$ extending up to a defect size of $21.5 \mathrm{~cm}$. The lesion measuring $21.5 \mathrm{~cm}$ was in patient 1 with a diagnosis of fibrous dysplasia. These results support the use of long donor grafts in large segment defects for the reconstruction in paediatric patients.

Regarding the vascularity of the graft, vascularised or nonvascularised grafts may be utilised depending on whether a blood



Fig. 7: Kaplan-Meier curve for time to revision

supply is transferred with the bone graft or not. There is no clear consensus in the literature to indicate which type of graft is more successful in the reconstructive setting. An article by Allsopp et al. suggested that vascularised grafts may actually increase the risk of complications without improving union rates or time to union. ${ }^{10}$ In another study, a mix of 53 adult and paediatric patients with a reconstructed primary sarcoma of bone were analysed by Schuh et al. in 2014. In this analysis, no difference was noted between 


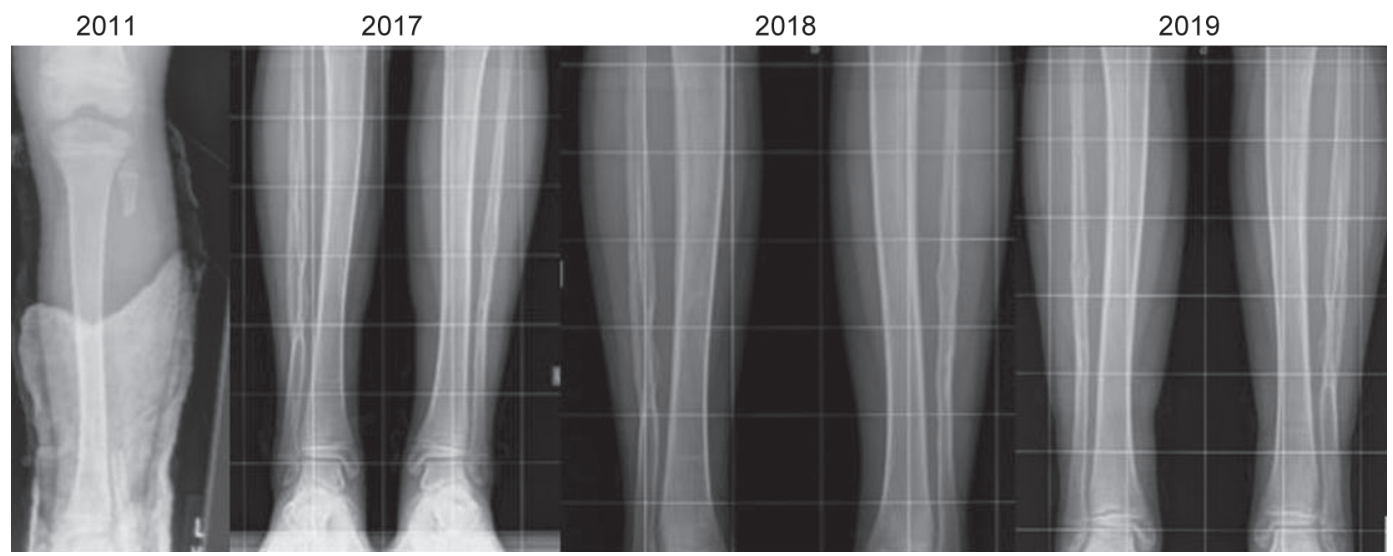

Fig. 8: Fibular donor site regeneration

vascularised and non-vascularised grafts in relation to union rates $(p=0.167) .{ }^{12}$ This study reported an overall union rate of $75 \%$. In keeping with this finding, we report a similar union rate of $80 \%$ in a paediatric cohort only. A pragmatic argument for non-vascularised over vascularised fibular graft is the fact that non-vascularised procedures are cheaper, faster and simpler to perform. ${ }^{13}$ The experience of the authors corroborates these sentiments. Another advantage to use a non-vascularised graft technique is noted with subperiosteal dissection which in turn allows the resected fibula to regenerate faster ${ }^{9}$ (Fig. 8). We noted this effect in a number of our cases and for these reasons we prefer to use non-vascularised graft in our institution when possible.

The majority of reports in the literature focus on adult samples or mixed adult and paediatric samples. Most paediatric studies in the literature are reported for benign lesions or posttraumatic bone defect reconstruction. ${ }^{14-17}$ We report on 10 cases involving a case-mix of both benign and malignant non-traumatic lesions in the paediatric setting only. The malignant lesions included three Ewing's sarcomas and two osteosarcomas. Both osteosarcomas underwent a chemotherapeutic regimen in line with the EURAMOS protocol for osteosarcoma. The Ewing's sarcoma patients all received neoadjuvant and adjuvant chemotherapy also. Radiation therapy of the chest was administered to patient 8 due to the presence of lung metastases on presentation. This patient then proceeded to develop an infected non-union which was later treated with an intercalary prosthesis. This represents the largest known cohort of malignant paediatric tumours reconstructed with avascular fibular autograft in the literature to date. Of the five malignant cases, there were no mortalities and no local or distant recurrences. These findings support the use of this technique in malignant bone tumour reconstruction in the paediatric setting but further larger scale analyses are warranted with continual follow-up. While comparing this technique to the induced-membrane technique for paediatric malignant tumours, we report lower rates of both non-union and fracture. ${ }^{18}$

Limitations include the small sample size and heterogeneous selection of cases. Given the lack of literature published on this technique in a paediatric cohort, these results are still very useful for the scientific community.

Overall, our complication rates of graft fracture, graft infection and revision are all in keeping with reported literature. ${ }^{19-21}$ We report a $20 \%$ rate of deep infection and non-union, a $40 \%$ rate of graft fracture and a $60 \%$ rate of revision surgery. This translates to 4 of the 10 patients undergoing comprehensive management with a single surgical episode for their pathology. Specific complications relating to donor ankle valgus deformity post-fibula harvesting have been reported in the literature. ${ }^{22}$ This was not an issue for any patients in our study, however.

\section{Conclusion}

The use of non-vascularised fibular autograft for the reconstruction of benign and malignant tumours is an effective surgical technique in a paediatric cohort. We report the largest known series of malignant paediatric tumours treated with this technique to date. Our results have been promising in this malignant cohort so far but further follow-up is required. Furthermore, larger scale studies should be conducted to analyse the results of non-vascularised fibular autograft in non-traumatic paediatric bone tumours.

\section{Clinical Significance}

Non-vascularised fibular autograft is successful in the reconstruction of large bone defects secondary to malignant paediatric bone tumours.

\section{References}

1. STROBE checklist Available from https://www.equator-network.org/ reporting-guidelines/strobe/.

2. Murray JA, Schlafly B. Giant-cell tumors in the distal end of the radius. Treatment by resection and fibular autograft interpositional arthrodesis. J Bone Joint Surg Am 1986;68(5):687-694. DOI: 10.2106/00004623-198668050-00008.

3. Fernyhough JC, White JI, LaRocca H. Fusion rates in multilevel cervical spondylosis comparing allograft fibula with autograft fibula in 126 patients. Spine 1991;16(10 Suppl):S561-S564. DOI: 10.1097/00007632199110001-00022.

4. Kashayi-Chowdojirao S, Vallurupalli A, Chilakamarri VK, et al. Role of autologous non-vascularised intramedullary fibular strut graft in humeral shaft nonunions following failed plating. J Clin Orthop Trauma 2017;8(Suppl. 2):S21-S30. DOI: 10.1016/j.jcot.2016.12.006.

5. Rengsen $\mathrm{P}$, Tiong K, Teo $\mathrm{Y}$, et al. Reconstruction of the second metatarsal with non-vascularised fibular graft following en-bloc resection for giant cell tumour: a case report. Malays Orthop J 2013;7(3):15-17. DOI: 10.5704/MOJ.1311.001.

6. Akiyama T, Clark JC, Miki Y, et al. The non-vascularised fibular graft: a simple and successful method of reconstruction of the pelvic ring after internal hemipelvectomy. J Bone Joint Surg Br 2010;92(7): 999-1005. DOI: 10.1302/0301-620X.92B7.23497.

7. Keizer SB, Kock NB, Dijkstra PD, et al. Treatment of avascular necrosis of the hip by a non-vascularised cortical graft. J Bone Joint Surg Br 2006;88(4):460-466. DOI: 10.1302/0301-620X.88B4.16950. 
8. Devireddy SK, Senthil Murugan M, Kishore Kumar RV, et al. Evaluation of non-vascular fibula graft for mandibular reconstruction. J Maxillofac Oral Surg 2015;14(2):299-307. DOI: 10.1007/s12663-0140657-1.

9. Lenze U, Pohlig F, Knebel C, et al. Autologous fibula transplantation for reconstruction of bone defects. Orthopade 2017;46(8):648-655. DOI: 10.1007/s00132-017-3442-2.

10. Allsopp BJ, Hunter-Smith DJ, Rozen WM. Vascularized versus nonvascularized bone grafts: what is the evidence? Clin Orthop Relat Res 2016;474(5):1319-1327. DOI: 10.1007/s11999-016-4769-4.

11. Lenze $U$, Kasal S, Hefti F, et al. Non-vascularised fibula grafts for reconstruction of segmental and hemicortical bone defects following meta-/diaphyseal tumour resection at the extremities. BMC Musculoskelet Disord 2017;18(1):289. DOI: 10.1186/s12891-017-1640-z.

12. Schuh R, Panotopoulos J, Puchner SE, et al. Vascularised or nonvascularised autologous fibular grafting for the reconstruction of a diaphyseal bone defect after resection of a musculoskeletal tumour. Bone Joint J 2014;96-B(9):1258-1263. DOI: 10.1302/0301620X.96B9.33230.

13. Krieg $A H$, Hefti $F$. Reconstruction with non-vascularised fibular grafts after resection of bone tumours. J Bone Joint Surg Br 2007;89(2): 215-221. DOI: 10.1302/0301-620X.89B2.17686.

14. Jamshidi K, Mirkazemi M, Izanloo A, et al. Locking plate and fibular strut-graft augmentation in the reconstruction of unicameral bone cyst of proximal femur in the paediatric population. Int Orthop 2018;42(1):169-174. DOI: 10.1007/s00264-017-3648-2.

15. Swamy MK, Rathi A, Gupta V. Results of non-vascularised fibular grafting in gap non-union of long bones in paediatric age group.
J Clin Orthop Trauma 2013;4(4):180-184. DOI: 10.1016/j.jcot.2013. 09.001.

16. Lampasi M, Magnani M, Donzelli O. Aneurysmal bone cysts of the distal fibula in children: Long-term results of curettage and resection in nine patients. J Bone Joint Surg Br 2007;89(10):1356-1362. DOI: 10.1302/0301-620X.89B10.19375.

17. Erickson C, Kaufmann W, Budimirovic D, et al. Best practices in fragile $X$ syndrome treatment development. Brain Sci 2018;8(12):224. DOI: 10.3390/brainsci8120224.

18. Villemagne T, Bonnard C, Accadbled F, et al. Intercalary segmental reconstruction of long bones after malignant bone tumor resection using primary methyl methacrylate cement spacer interposition and secondary bone grafting: the induced membrane technique. J Pediatr Orthop 2011;31(5):570-576. DOI: 10.1097/BPO.0b013e31821ffa82.

19. Ortiz-Cruz E, Gebhardt MC, Jennings LC, et al. The results of transplantation of intercalary allografts after resection of tumors. A long-term follow-up study. J Bone Joint Surg Am 1997;79(1):97-106. DOI: 10.2106/00004623-199701000-00010.

20. Mankin HJ, Springfield DS, Gebhardt MC, et al. Current status of allografting for bone tumors. Orthopedics 1992;15(10):1147-1154.

21. Zekry KM, Yamamoto N, Hayashi K, et al. Reconstruction of intercalary bone defect after resection of malignant bone tumor. J Orthop Surg (Hong Kong) 2019;27(1):2309499019832970. DOI: 10.1177/2309499019832970.

22. Agarwal A, Kumar D, Agrawal N, et al. Ankle valgus following non-vascularized fibular grafts in children-an outcome evaluation minimum two years after fibular harvest. Int Orthop 2017;41(5): 949-955. DOI: 10.1007/s00264-017-3403-8. 